\title{
Surgical strategy for refractory epilepsy secondary to porencephaly: ictal SPECT may obviate the need for intracranial electroencephalography. Patient series
}

\author{
Naoki Ichikawa, MD, PhD, ${ }^{1}$ Naotaka Usui, MD, PhD, ${ }^{1}$ Akihiko Kondo, MD, PhD, ${ }^{1}$ Takayasu Tottori, MD, PhD, ${ }^{1}$ Tokito Yamaguchi, MD, ${ }^{2}$ \\ Hirowo Omatsu, MD, ${ }^{2}$ Takayoshi Koike, MD, ${ }^{2}$ Hiroko Ikeda, MD, ${ }^{2}$ Katsumi Imai, MD, ${ }^{2}$ and Yukitoshi Takahashi, MD, PhD ${ }^{2}$ \\ Departments of ${ }^{1}$ Neurosurgery and ${ }^{2}$ Pediatrics, National Epilepsy Center, NHO Shizuoka Institute of Epilepsy and Neurological Disorders, Shizuoka, Japan
}

BACKGROUND Surgical treatment of intractable epilepsy caused by porencephaly can be difficult because of poorly localizing or lateralizing electroclinical findings. The authors aimed to determine whether noninvasive evaluations are sufficient in these patients.

OBSERVATIONS Eleven patients were included in this study. The porencephalic cyst was in the left middle cerebral artery (MCA) area in 9 patients, the left posterior cerebral artery area in 1 patient, and the bilateral MCA area in 1 patient. Interictal electroencephalography (EEG) revealed multiregional, bilateral, interictal epileptiform discharges in 5 of 11 patients. In 6 of 10 patients whose seizures were recorded, the ictal EEG was nonlateralizing. Nine patients underwent ictal single-photon emission computed tomography (SPECT), which revealed lateralized hyperperfusion in 8 of 9 cases. Fluorodeoxyglucose positron emission tomography (FDG-PET) was useful for identifying the functional deficit zone. No patient had intracranial EEG. The procedure performed was hemispherotomy in 7 patients, posterior quadrant disconnection in 3 patients, and occipital disconnection in 1 patient. A favorable seizure outcome was achieved in 10 of 11 patients without the onset of new neurological deficits.

LESSONS Ictal SPECT was useful for confirming the side of seizure origin when electroclinical findings were inconclusive. Thorough noninvasive evaluations, including FDG-PET and ictal SPECT, enabled curative surgery without intracranial EEG. Seizure and functional outcomes were favorable.

https://thejns.org/doi/abs/10.3171/CASE21121

KEYWORDS epilepsy surgery; porencephaly; ictal SPECT

A porencephalic cyst is a rare condition of cerebrospinal fluid (CSF) accumulation within the brain parenchyma, with an incidence of 3.5 to 5.2 cases per 100,000 live births. ${ }^{1,2}$ It is usually related to perinatal vascular events, including cerebral ischemia or hemorrhage. ${ }^{1}$ The cyst is usually single and unilateral, but multiple or bilateral cysts have also been reported. These cysts can have a wide array of clinical presentations, including epilepsy. ${ }^{3}$ Although children are rarely affected by ischemic or hemorrhagic stroke, up to twothirds of patients who experience perinatal infarction will eventually develop epilepsy, and in $25 \%$ of these cases, the seizures will be medically intractable. ${ }^{4,5}$ Compared with the number of reports of surgical treatment for childhood epilepsy secondary to malformations of cortical development and benign tumors, few reports have focused on epilepsy due to stroke or other vasculogenic causes in children, including porencephaly. Determining the best surgical strategy for these candidates can be difficult because the cortical injury can be widespread or multilobar, electroclinical findings can be multifocal or poorly lateralizing, and functional reserve can be limited. However, some reports suggest that intracranial electroencephalography (EEG) or intraoperative electrocorticography can be useful for presurgical decision-making for epilepsy secondary to porencephaly. ${ }^{6-8}$ In 11 patients with porencephaly, we performed thorough noninvasive presurgical evaluations followed by curative epilepsy surgery and obtained favorable outcomes. In the present study, we aimed to determine

ABBREVIATIONS CSF = cerebrospinal fluid; EEG = electroencephalography; FDG-PET = fluorodeoxyglucose positron emission tomography; FLAIR = fluid-attenuated inversion recovery; IED = interictal epileptiform discharge; $\mathrm{MCA}=$ middle cerebral artery; $\mathrm{MRI}=$ magnetic resonance imaging; SISCOM = subtraction ictal single-photon emission computed tomography coregistered to magnetic resonance imaging; SPECT = single-photon emission computed tomography.

INCLUDE WHEN CITING Published May 24, 2021; DOI: 10.3171/CASE21121.

SUBMITTED February 22, 2021. ACCEPTED March 25, 2021.

(C) 2021 The authors, CC BY-NC-ND 4.0 (http://creativecommons.org/licenses/by-nc-nd/4.0/). 
whether noninvasive preoperative evaluations are sufficient to accurately identify the epileptogenic zone in these patients.

\section{Study Description}

\section{Study Design and Ethics Approval}

The ethics committee at the National Epilepsy Center, NHO Shizuoka Institute of Epilepsy and Neurological Disorders approved the protocol for this study in accordance with the principles of the Declaration of Helsinki. Participants in this study were identified via retrospective electronic chart review at the National Epilepsy Center, NHO Shizuoka Institute of Epilepsy and Neurological Disorders. Written informed consent was obtained from all patients or their families.

\section{Patients}

Using the electronic medical records in our institute between October 2009 and April 2020, we investigated patients of all ages who were diagnosed with intractable focal epilepsy caused by porencephaly. Of this group, only the patients who underwent epilepsy surgery were included in this study. We examined their clinical characteristics, the results of comprehensive presurgical evaluations, the surgical technique used, surgical complications, postoperative follow-up duration, postoperative seizure outcomes, and postoperative neuropsychological and developmental outcomes.

We diagnosed porencephaly when a lesion fulfilled the following magnetic resonance imaging (MRI) criteria: a cyst lined by white matter and containing CSF that has low signal intensity on T1-weighted and fluid-attenuated inversion recovery (FLAIR) sequences, high signal intensity on T2-weighted sequences, and no restricted diffusion. ${ }^{9}$

\section{Comprehensive Preoperative Evaluations}

We reviewed the results of presurgical examinations in the patients included in the study. Comprehensive preoperative evaluations included neurological examinations (especially motor and visual field tests), neuropsychological tests, head MRI, long-term video-EEG monitoring, fluorodeoxyglucose positron emission tomography (FDG-PET), interictal and ictal single-photon emission computed tomography (SPECT), and the Wada test. The standard 10-20 system of electrode placement was used for EEG recording. Brain MRI was performed at $3.0 \mathrm{~T}$ in 9 patients and at $1.5 \mathrm{~T}$ in 2 patients. Axial, coronal, and sagittal T1-weighted, T2-weighted, and FLAIR images were acquired. Ictal SPECT was performed in patients with frequent seizures. Whenever possible, isotope injection was performed during video-EEG monitoring, and the delay between seizure onset and injection was recorded. Neuropsychological testing was performed using the Japanese version of the Wechsler Adult Intelligence Scale 3rd edition in 2 patients, the Wechsler Intelligence Scale for Children 4th edition in 1 patient, the Tanaka-Binet test in 1 patient, and the Kyoto Scale of Psychological Development 2001 and Tsumori developmental inquiry schedule in 7 patients.

\section{Outcome Measurement}

Postoperative seizure outcomes were determined in accordance with Engel's criteria ${ }^{10}$ from information obtained at the most recent visit. In addition, in 6 patients, we compared the results of neuropsychological tests administered 2 years after surgery with those of the same battery of tests administered preoperatively.

\section{Patient Characteristics}

We identified 25 patients who were diagnosed with epilepsy caused by porencephaly, and among them, 11 patients underwent curative surgery for porencephalic epilepsy. Thus, we included these 11 patients in this study. In the same period, 559 patients underwent resective epilepsy surgery in our institute. Demographics are shown in Table 1. In 14 patients who did not undergo epilepsy surgery, all had head MRI and scalp EEG, and 3 of them underwent comprehensive preoperative evaluations. The breakdown of their reasons for not having surgery were the following: satisfactory seizure control in 6 , patient refusal of proposed surgery in 5 , and severe motor and intellectual disability not amenable to surgery in 3 . All 11 patients who underwent surgery had a history of perinatal stroke events and were affected on the left side of the brain. There was no other medical history, such as status epilepticus, head trauma, or central nervous system infections. One patient experienced meconium aspiration syndrome and had several febrile convulsions. Preoperative neurological examination revealed right hemiparesis involving loss of fine finger movements in 10 patients (7 ambulatory and 3 needing a wheelchair). Formal visual field testing was performed in 3 patients; 2 had right hemianopia, and 1 had right lower quadrantanopia (Table 2). Formal visual field testing was not possible in the remaining 8 patients because of young age or intellectual disability.

\section{Preoperative Evaluations}

All 11 patients underwent long-term video-EEG monitoring, head MRI, interictal SPECT, and neuropsychological testing. Ten patients $(90.9 \%)$ had interictal FDG-PET, $9(81.8 \%)$ had ictal SPECT, and 4 $(36.4 \%)$ had a Wada test. No patient underwent intracranial EEG.

In head MRI findings, 10 patients had porencephaly in the circulation area of the middle cerebral artery (MCA), and 1 patient had porencephaly in the circulation area of the posterior cerebral artery (Fig. 1). All 10 patients who had porencephaly in the MCA area also demonstrated pyramidal tract disconnection and left cerebral peduncle atrophy. Ten patients were affected on the left side, and 1 patient was affected bilaterally. The porencephaly was located in

TABLE 1. Patient demographics and preoperative studies ( $N=11$ patients)

\begin{tabular}{lc}
\hline \multicolumn{1}{c}{ Characteristic } & Value \\
\hline Female sex, no. (\%) & $6(54.5)$ \\
\hline Age at seizure onset, mean (range), yrs & $3.13(0-14)$ \\
\hline Age at surgery, mean (range), yrs & $9.55(4-23)$ \\
\hline Epilepsy duration, mean (range), yrs & $6.42(3-22.5)$ \\
\hline Follow-up duration, mean (range), mos & $29.9(7-60)$ \\
\hline Head MRI, no. (\%) & $11(100)$ \\
\hline Long-term scalp EEG, no. (\%) & $11(100)$ \\
\hline Interictal SPECT, no. (\%) & $11(100)$ \\
\hline Neuropsychological testing, no. (\%) & $11(100)$ \\
\hline Interictal FDG-PET, no. (\%) & $10(90.9)$ \\
\hline Ictal SPECT/SISCOM, no. (\%) & $9(81.8)$ \\
\hline Wada test, no. (\%) & $4(36.4)$ \\
\hline Intracranial EEG, no. (\%) & $0(0)$ \\
\hline
\end{tabular}


TABLE 2. Clinical characteristics of the 11 patients

\begin{tabular}{|c|c|c|c|c|c|c|c|c|}
\hline Case No. & Diagnosis & Sex & $\begin{array}{c}\text { Age at } \\
\text { Epilepsy Onset }\end{array}$ & $\begin{array}{l}\text { Age at } \\
\text { Surgery }\end{array}$ & Clinical History & Motor Deficit & $\begin{array}{l}\text { Visual Field } \\
\text { Defect }\end{array}$ & Seizure Type (frequency) \\
\hline 1 & SLRE & $\mathrm{F}$ & $3 \mathrm{mos}$ & 5 yrs & Perinatal ischemia & $\begin{array}{l}\text { Hemiparesis; } \\
\text { wheelchair }\end{array}$ & NA & Focal tonic seizure (daily) \\
\hline 2 & SLRE & $\mathrm{F}$ & $3 \mathrm{mos}$ & $5 \mathrm{yrs}$ & Perinatal ischemia & $\begin{array}{l}\text { Hemiparesis; } \\
\text { wheelchair }\end{array}$ & NA & Focal tonic seizure (daily) \\
\hline 3 & OLE & $\mathrm{F}$ & $14 \mathrm{yrs}$ & $21 \mathrm{yrs}$ & Perinatal ischemia & $\begin{array}{l}\text { Hemiparesis; } \\
\text { ambulatory }\end{array}$ & Rt $1 / 2$ & $\begin{array}{l}\text { Focal visual seizure, focal } \\
\text { automatism seizure, FBTCS } \\
\text { (weekly) }\end{array}$ \\
\hline 4 & SLRE & $\mathrm{F}$ & $1 \mathrm{yr}$ & $4 \mathrm{yrs}$ & Perinatal hemorrhage & $\begin{array}{l}\text { Hemiparesis; } \\
\text { ambulatory }\end{array}$ & NA & $\begin{array}{l}\text { Focal impaired awareness } \\
\text { automatism seizure (monthly) }\end{array}$ \\
\hline 5 & OLE & M & $7 \mathrm{yrs}$ & 12 yrs & Perinatal ischemia & None & $\begin{array}{c}\text { Rt lower } \\
1 / 4\end{array}$ & $\begin{array}{l}\text { Focal visual seizure, FIAS } \\
\text { (weekly) }\end{array}$ \\
\hline 6 & SLRE & M & $1 \mathrm{yr}$ & $5 \mathrm{yrs}$ & $\begin{array}{l}\text { MAS, FC, perinatal } \\
\text { ischemia }\end{array}$ & $\begin{array}{l}\text { Hemiparesis; } \\
\text { ambulatory }\end{array}$ & NA & Focal tonic seizure, MS (daily) \\
\hline 7 & WS, SLRE & $\mathrm{F}$ & $6 \mathrm{mos}$ & 23 yrs & Perinatal ischemia & $\begin{array}{l}\text { Hemiparesis; } \\
\text { ambulatory }\end{array}$ & NA & Focal motor seizure (monthly) \\
\hline 8 & SLRE & M & 6 mos & 5 yrs & Perinatal ischemia & $\begin{array}{l}\text { Hemiparesis; } \\
\text { ambulatory }\end{array}$ & NA & $\begin{array}{l}\text { Focal tonic seizure, focal MS } \\
\text { (daily) }\end{array}$ \\
\hline 9 & PCE & $\mathrm{M}$ & $10 \mathrm{yrs}$ & $16 \mathrm{yrs}$ & Perinatal ischemia & $\begin{array}{l}\text { Hemiparesis; } \\
\text { ambulatory }\end{array}$ & Rt $1 / 2$ & $\begin{array}{l}\text { Focal impaired awareness } \\
\text { motor seizure (weekly) }\end{array}$ \\
\hline 10 & WS, SLRE & $\mathrm{M}$ & 4 mos & 4 yrs & Perinatal ischemia & $\begin{array}{l}\text { Hemiparesis; } \\
\text { ambulatory }\end{array}$ & NA & Focal ES (daily) \\
\hline 11 & PCE & $\mathrm{F}$ & $7 \mathrm{mos}$ & 5 yrs & Perinatal ischemia & $\begin{array}{l}\text { Tetraparesis; } \\
\text { wheelchair }\end{array}$ & NA & $\begin{array}{l}\text { Focal tonic seizure (startle), MS } \\
\text { (daily) }\end{array}$ \\
\hline
\end{tabular}

ES = epileptic spasms; FBTCS = focal to bilateral tonic-clonic seizure; FC = febrile convulsion; FIAS = focal impaired awareness seizure; MAS = meconium aspiration syndrome; MS = myoclonic seizure; NA = not available; OLE = occipital lobe epilepsy; PCE = posterior cortex epilepsy; SLRE = symptomatic localization-related epilepsy; WS $=$ West syndrome.

the frontoparietotemporal area in 9 cases, in the parieto-occipital area in 1 case, and in the frontal area in 1 case.

Habitual seizures were recorded during video-EEG monitoring in 10 of the 11 patients. Eight of the 10 patients whose seizures were recorded during video-EEG monitoring showed lateralizing signs in semiology, such as tonic activity of the right limbs, right version, and a right figure 4 sign. The remaining 2 patients had no definite lateralizing signs. On EEG, regional interictal epileptiform discharges (IEDs) were seen exclusively on the left side in 4 patients (cases 3, 4, 5, and 9) and in the midline in 2 (cases 7 and 11). In the remaining 5 patients (cases 1,2, 6, 8, and 10), multiregional IEDs were seen in both hemispheres. Ictal EEG revealed regional onset in the left side in 2 patients (cases 5 and 9) and regional onset in the midline in 2 (cases 7 and 11). However, in the remaining 6 patients, ictal EEG revealed nonlateralizing onset.

Ten patients underwent FDG-PET, which showed hypometabolism in various regions in the left hemisphere (Table 3). Nine patients underwent ictal SPECT and had subtraction ictal SPECT coregistered to MRI (SISCOM). The timing of isotope injection was available in 8 of the 9 patients and ranged from 2 to 50 seconds. The regions of hyperperfusion varied in location and extent, but all were in the left hemisphere (Table 3). The Wada test demonstrated that language dominance was on the right side in all 4 patients in whom it was performed. Neuropsychological tests indicated some degree of intellectual disability in all patients.

\section{Surgical Procedures}

The procedures performed were hemispherotomy via a lateral approach in 7 patients $(63.6 \%)$, posterior quadrant disconnection in 3 patients (27.3\%), and occipital disconnection in 1 patient $(9.1 \%)$. One patient developed hydrocephalus after hemispherotomy and needed a ventriculoperitoneal shunt, but no patient developed a new, permanent neurological deficit postoperatively.

\section{Seizure Outcome and Neuropsychological Outcome}

A favorable outcome (Engel class I and II) was obtained in $90.9 \%$ of the 11 patients (Table 3 ). No significant neuropsychological worsening was seen in the 6 patients whose data were available (Table 3).

\section{Illustrative Cases}

\section{Favorable Outcome: Case 6}

The patient was a 5-year-old boy at the time of surgery. He was born at 41 weeks 2 days and weighed 3,196 g. His Apgar score was $8 / 9$. At birth, he had meconium aspiration syndrome and needed respiratory management for 2 days. On day 5 , head computed tomography led to a diagnosis of left hemisphere infarction caused by left MCA occlusion. His other medical history included uncomplicated febrile convulsions. His seizures began when he was 1 year old. Medical therapy was started, but sei-zures could not be controlled even with 6 medications (clobazam, clonazepam, 

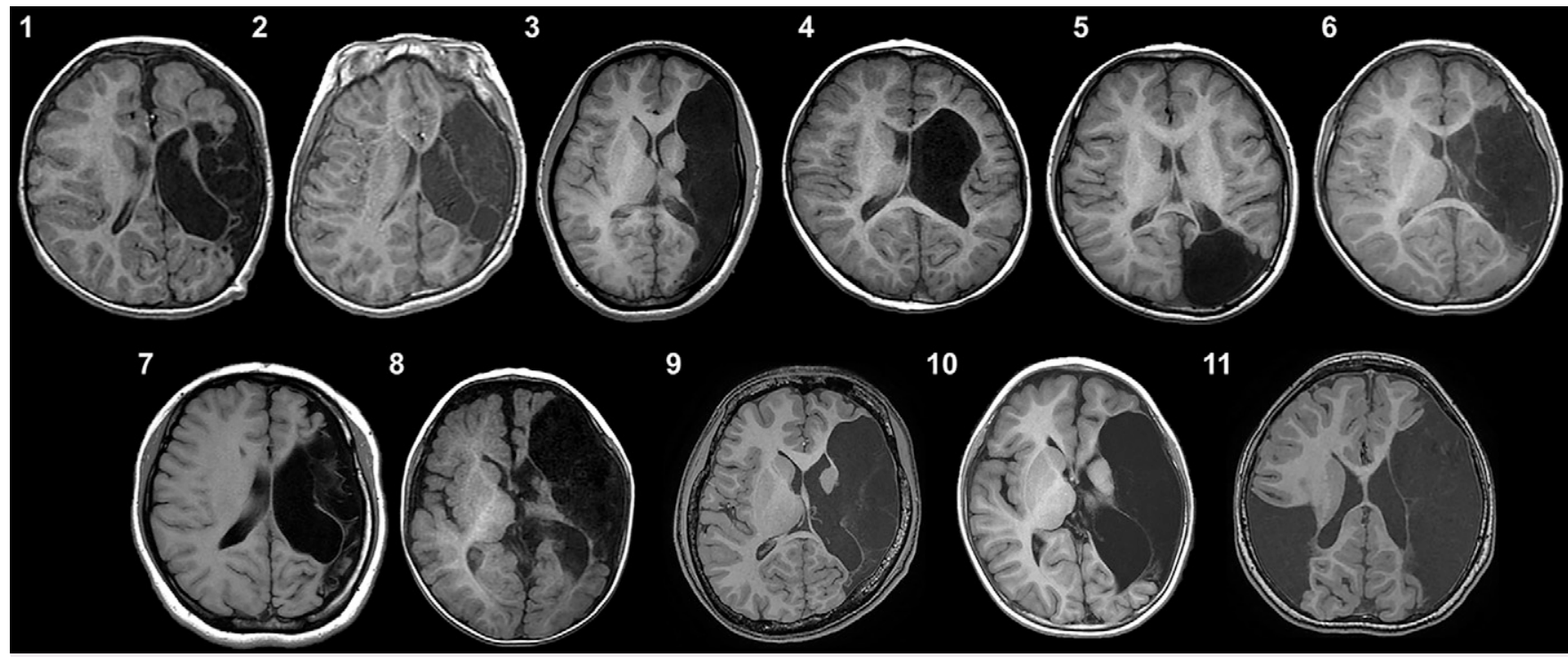

10

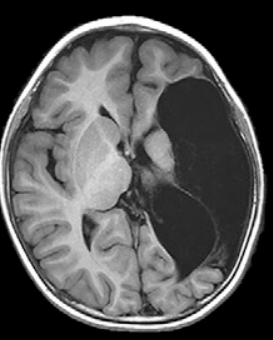

11

FIG. 1. Axial T1-weighted MRI scans showing the appearance of porencephaly in all patients of this study. Case numbers are shown. All patients experienced perinatal ischemia, except for the patient in case 4, who experienced perinatal hemorrhage. The porencephalic cyst in the patient in case 4 occupied the frontal area, that of the patient in case 5 the parieto-occipital area, and all others the frontoparietotemporal area.

gabapentin, levetiracetam, sulthiame, and zonisamide). At 4 years old, he visited our epilepsy center. He had right hemiparesis but was able to walk by himself. He could not grasp with his right hand. He had daily focal motor seizures characterized by tonic extension of the arms bilaterally, predominantly on the right side, and he occasionally fell to the ground. He also had myoclonic seizures during sleep. Interictal EEG revealed spikes in the left frontal, left occipital, and right occipital regions; the ictal discharges were nonlateralizing but larger in amplitude on the right. MRI demonstrated a large porencephalic cyst in the left MCA territory (Fig. 2A). The pyramidal tract from the left hemisphere was disconnected, and the left cerebral peduncle was atrophic (Fig. 2B). There were no notable abnormalities in the right hemisphere on MRI. FDG-PET demonstrated extensive hypometabolism in the left hemisphere (Fig. 2C). Ictal SPECT showed hyperperfusion in the left frontal and left occipital areas (Fig. 2D). His developmental quotient was 47 according to the Kyoto Scale of Psychological Development 2001. Seizure onset lateralization could not be determined on the basis of his semiology and EEG findings; however, ictal SPECT provided a strong indication that his seizures originated from the left hemisphere, ipsilateral to the porencephalic cyst. He already had right hemiparesis, and FDG-PET suggested that his functional deficit zone involved the whole left hemisphere. Left hemispherotomy was performed. He became completely seizure free (class la). A Tanaka-Binet test administered 2 years after surgery revealed an intelligence quotient of 57 .

\section{Unfavorable Outcome: Case 1}

The patient was a 5-year-old girl. She had no significant clinical history other than perinatal ischemia. The age at seizure onset was 3 months. Her seizure type was daily focal tonic seizure of the right arm. Her EEG showed bilateral multiregional IEDs and nonlateralizing ictal discharges. MRI demonstrated a porencephalic cyst in the left MCA territory. FDG-PET was not performed. Ictal SPECT showed hyperperfusion in the left frontal and parietal areas. On the basis of these noninvasive data, we performed left hemispherotomy. One month after surgery, she presented with hydrocephalus, and she underwent ventriculoperitoneal shunt placement. She had been seizure free for 2.5 years after surgery until a reduction of clorazepate. Then, her focal tonic seizures recurred, and the seizures have been intractable until now. It is possible that the reduction of antiepileptic drug altered the seizure outcome in this patient.

\section{Discussion}

\section{Observations}

Previous reports have recommended intracranial EEG or intraoperative electrocorticography to identify the site of epileptogenesis and to plan a surgical strategy in patients with porencephaly. ${ }^{6-8}$ In this study, we reviewed the cases of patients who underwent surgery to treat refractory epilepsy secondary to porencephaly at our institute. None of the 11 patients needed intracranial EEG monitoring, thereby sparing them an invasive procedure that has definite risks, such as infection, hemorrhage, and infarction. It is also important to avoid the costs of intracranial EEG monitoring when it is not necessary. Ictal SPECT was useful for confirming the side of seizure origin. Noninvasive evaluations, including ictal SPECT and FDG-PET, contributed to final surgical decision-making without intracranial EEG.

\section{Etiology and Preoperative Neurological Function}

All 11 patients had a history of perinatal stroke (10 ischemia, 1 hemorrhage) leading to porencephaly. Perinatal stroke, especially cerebral artery occlusion, has been described as the most common cause of porencephaly. ${ }^{11-14}$ All of our patients were affected on the left side (with 1 patient affected on both sides), and 10 patients had left MCA occlusion. This predominance of lesions on the left side has been described previously ${ }^{15-17}$ and is thought to be attributable to differences in vulnerability and maturation or to the presence of vascular asymmetries. ${ }^{15}$ The left hemisphere might be vulnerable to embolic lesions caused by hemodynamic differences from a patent 


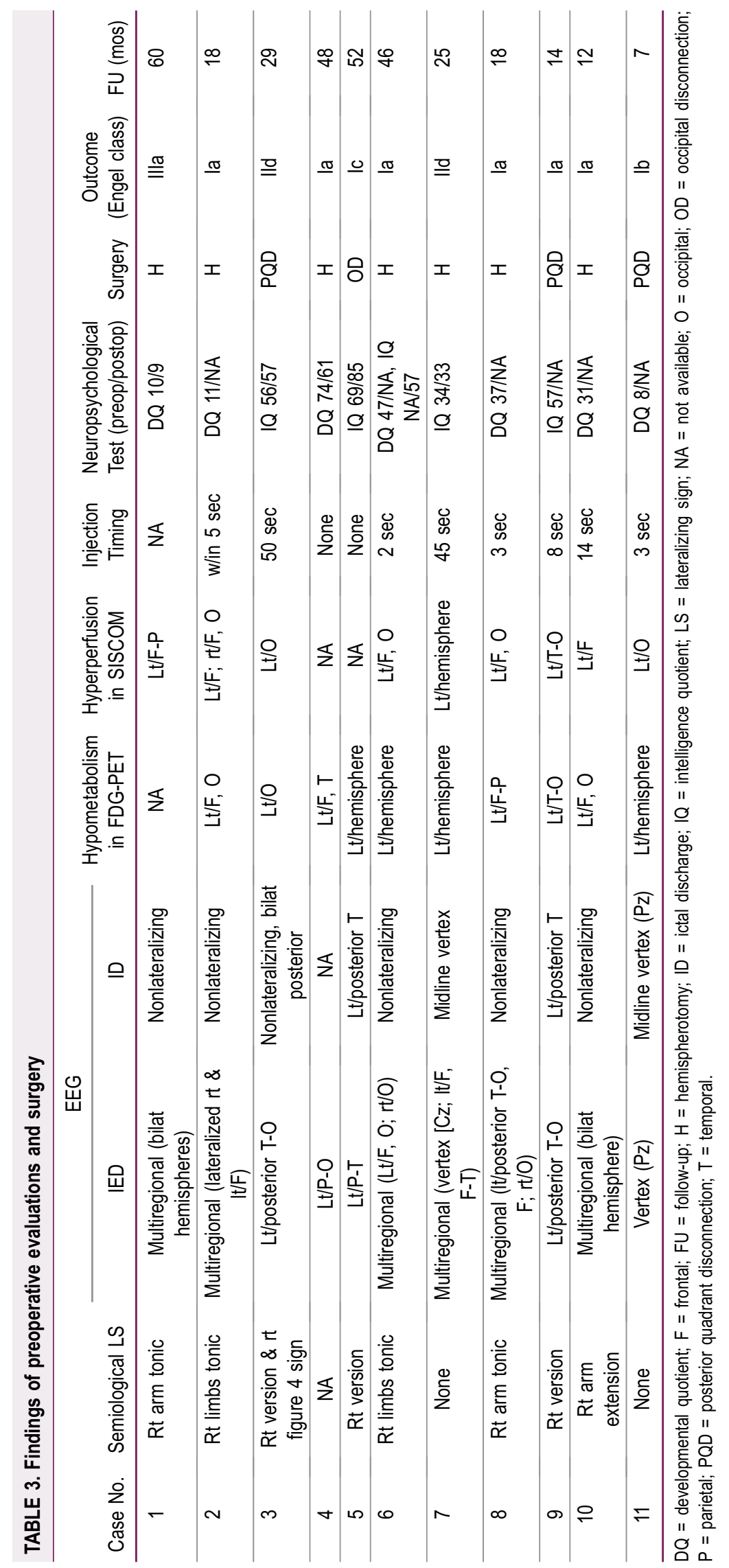

J Neurosurg Case Lessons | Vol 1 | Issue 21 | May 24, 2021 | 5 

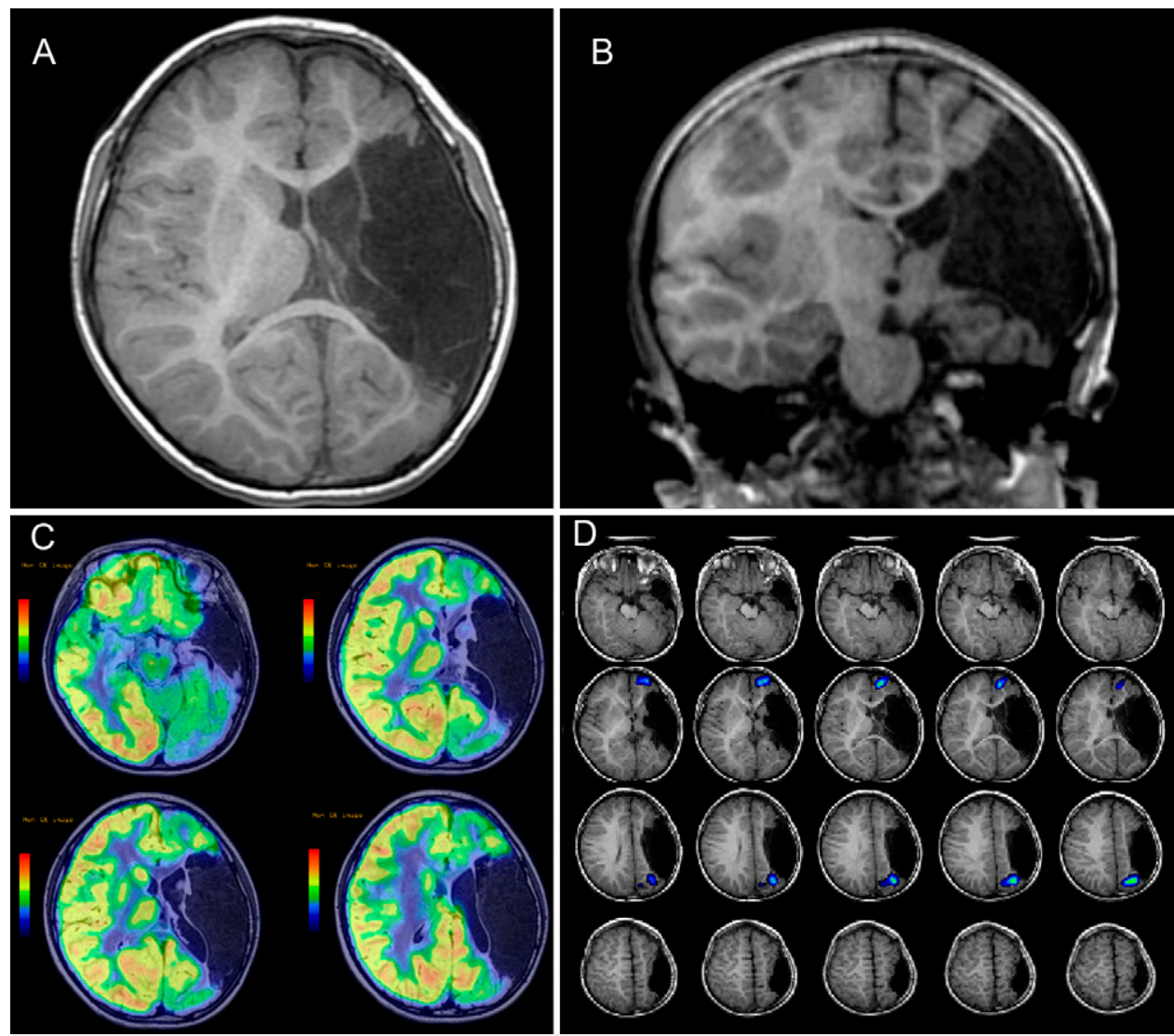

FIG. 2. Preoperative imaging studies in case 6 . A: T1-weighted axial MRI showing a porencephalic cyst in the left frontoparietotemporal area. B: Coronal MRI study showing the left pyramidal tract disconnection and cerebral peduncle atrophy. C: FDG-PET showing extensive hypometabolism in the left hemisphere. D: SISCOM showing hyperperfusion (b/ue) in the left frontal and occipital areas.

ductus arteriosus or through a direct route involving the left common carotid artery. ${ }^{15,16}$

Preoperatively, 10 patients had right hemiparesis, 7 of whom were ambulatory and 3 of whom needed a wheelchair. Seven patients who underwent hemispherotomy had right hemiparesis involving the loss of fine finger movements preoperatively, and postoperatively they had no worsening of neurological deficits. Previous reports have indicated that patients with congenital hemiparesis are good candidates for hemispherectomy, which is an appropriate surgical procedure for patients with porencephaly secondary to prenatal stroke or perinatal MCA occlusion. ${ }^{18-21}$ Three patients had visual field defects confirmed by formal visual field testing preoperatively. In the remaining 8 patients, formal visual field testing was not possible because of young age, intellectual disability, or both, but they may also have had visual field defects preoperatively, considering the presence and location of the large porencephalic cysts on MRI.

\section{Preoperative Evaluations and Surgical Strategy}

Ictal onset lateralization was not determined in 8 patients, including 2 patients with regional midline onset. Even EEG did not allow us to definitively determine the lateralization of seizure onset in these patients. Evaluation of contralateral epileptogenesis is important for deciding whether hemispherotomy is indicated, and ictal SPECT provides useful information regarding the seizure onset zone in this context. SISCOM revealed ictal hyperperfusion on the left side ipsilateral to the porencephalic cysts in 8 patients and hyperperfusion bilaterally in 1 patient. Ictal SPECT was therefore useful for the final surgical decision-making and removed the need for intracranial EEG, which Ghatan et al. reported to be helpful in ruling out bilateral epileptogenesis in suspected bilateral cases. ${ }^{7}$ However, in the present study, ictal SPECT was very useful for the same purpose. From a functional standpoint, all 7 patients who underwent hemispherotomy had right hemiparesis preoperatively, and MRI revealed disruption of the pyramidal tract; thus, hemispherectomy was not expected to produce further deficits. FDG-PET was also helpful for confirming that the left hemisphere was dysfunctional and the right hemisphere maintained function. The Wada test was considered necessary in 4 cases, including 1 patient who underwent hemispherotomy, to confirm that the surgical hemisphere had no language function.

In 4 patients, including 3 who underwent posterior quadrant disconnection and 1 who underwent occipital disconnection, electroclinical features provided sufficient information to localize the seizure origin. Ictal SPECT was performed in 3 of these 4 patients and provided concordant data in all 3. We considered intracranial EEG to be unnecessary in these patients as well. 
Thus, patients with intractable epilepsy caused by large porencephalic cysts can proceed to surgery after a thorough noninvasive evaluation. In these patients, ictal SPECT provides useful information, especially when semiology and EEG findings are nonlateralizing. The functional deficit zones in these patients are usually widespread, and neurological examinations and evaluation of cerebral dysfunction by FDG-PET are essential. Extensive noninvasive evaluations including ictal SPECT and FDG-PET obviate the need for intracranial EEG.

\section{Postoperative Outcome}

Ten $(90.9 \%)$ of the 11 patients had a favorable seizure outcome (Engel class I, II) at the last follow-up evaluation. In 1 of 3 patients who underwent posterior quadrant disconnection, the Engel class was IId. In this patient, seizures originating from the left frontopolar region were recorded on EEG during sleep. She is not aware of her seizures, and the seizures are not disabling; however, the outcome might have been better if we had performed a hemispherotomy in this case. There was also 1 case with Engel class III after hemispherotomy, suggesting that an epileptogenic focus was also present in the contralateral side. In this case, preoperative interictal EEG revealed multiregional spikes in both hemispheres, and ictal EEG was nonlateralizing. We believe that our patients' outcomes are consistent with those in prior surgical series. ${ }^{22,23}$

Limitations of this study include the retrospective design, lack of a control group, and small sample size. Nonetheless, we hope that the data presented here will help clinicians and patients with refractory epilepsy secondary to porencephaly make appropriate decisions regarding surgery.

\section{Lessons}

Ictal SPECT was useful for confirming the side of seizure origin, especially when electroclinical findings were inconclusive. Thorough noninvasive evaluations, including FDG-PET and ictal SPECT, led to curative surgery without the need for intracranial EEG. Seizure and functional outcomes were favorable.

\section{References}

1. Hino-Fukuyo N, Togashi N, Takahashi R, et al. Neuroepidemiology of porencephaly, schizencephaly, and hydranencephaly in Miyagi Prefecture, Japan. Pediatr Neurol. 2016;54:39-42.e1.

2. Husain T, Langlois PH, Sever LE, Gambello MJ. Descriptive epidemiologic features shared by birth defects thought to be related to vascular disruption in Texas, 1996-2002. Birth Defects Res A Clin Mol Teratol. 2008;82(6):435-440.

3. Ho SS, Kuzniecky RI, Gilliam F, et al. Congenital porencephaly: MR features and relationship to hippocampal sclerosis. AJNR Am J Neuroradiol. 1998;19(1):135-141.

4. Golomb MR, Garg BP, Carvalho KS, et al. Perinatal stroke and the risk of developing childhood epilepsy. J Pediatr. 2007;151(4):409-413.e2.

5. Fitzgerald KC, Williams LS, Garg BP, Golomb MR. Epilepsy in children with delayed presentation of perinatal stroke. J Child Neurol. 2007;22(11):1274-1280.

6. Marchi A, Pennaroli D, Lagarde S, et al. Epileptogenicity and surgical outcome in post stroke drug resistant epilepsy in children and adults. Epilepsy Res. 2019;155:106155.

7. Ghatan S, McGoldrick P, Palmese C, et al. Surgical management of medically refractory epilepsy due to early childhood stroke.

J Neurosurg Pediatr. 2014;14(1):58-67.
8. lida K, Otsubo H, Arita K, et al. Cortical resection with electrocorticography for intractable porencephaly-related partial epilepsy. Epilepsia. 2005;46(1):76-83.

9. Oommen AT, Sethy G, Minz NT, et al. Unusual presentation of porencephalic cyst in an adult. J Clin Diagn Res. 2017;11(2):OD12OD13.

10. Engel J Jr. Surgical Treatment of the Epilepsies. Raven Press; 1987.

11. Kolawole TM, Patel PJ, Mahdi AH. Porencephaly: computed tomography (CT) scan findings. Comput Radiol. 1987;11(1):53-58.

12. Barth PG. Prenatal clastic encephalopathies. Clin Neurol Neurosurg. 1984;86(2):65-75.

13. Kotlarek F, Rodewig R, Brüll D, Zeumer H. Computed tomographic findings in congenital hemiparesis in childhood and their relation to etiology and prognosis. Neuropediatrics. 1981;12(2):101-109.

14. Naef RW. Clinical features of porencephaly; a review of thirty-two cases. AMA Arch Neurol Psychiatry. 1958;80(2):133-147.

15. Salih MA, Abdel-Gader AG, Al-Jarallah AA, et al. Perinatal stroke in Saudi children. Clinical features and risk factors. Saudi Med J. 2006;27(suppl 1):S35-S40.

16. Sreenan $C$, Bhargava R, Robertson CM. Cerebral infarction in the term newborn: clinical presentation and long-term outcome. J Pediatr. 2000;137(3):351-355.

17. Perlman JM, Rollins NK, Evans D. Neonatal stroke: clinical characteristics and cerebral blood flow velocity measurements. Pediatr Neurol. 1994;11(4):281-284.

18. Holthausen H, Strobl K. Modes of reorganization of the sensorimotor system in children with infantile hemiplegia and after hemispherectomy. Adv Neurol. 1999;81:201-220.

19. Schramm J, Behrens E, Entzian W. Hemispherical deafferentation: an alternative to functional hemispherectomy. Neurosurgery. 1995; 36(3):509-516.

20. Tinuper P, Andermann F, Villemure JG, et al. Functional hemispherectomy for treatment of epilepsy associated with hemiplegia: rationale, indications, results, and comparison with callosotomy. Ann Neurol. 1988;24(1):27-34.

21. Verity CM, Strauss EH, Moyes PD, et al. Long-term follow-up after cerebral hemispherectomy: neurophysiologic, radiologic, and psychological findings. Neurology. 1982;32(6):629-639.

22. Scavarda D, Major P, Lortie A, et al. Periinsular hemispherotomy in children with stroke-induced refractory epilepsy. J Neurosurg Pediatr. 2009;3(2):115-120.

23. Guzzetta F, Battaglia D, Di Rocco C, Caldarelli M. Symptomatic epilepsy in children with poroencephalic cysts secondary to perinatal middle cerebral artery occlusion. Childs Nerv Syst. 2006;22(8):922-930.

\section{Disclosures}

Dr. Takahashi reports receiving an academic donation from Eisai Co.

\section{Author Contributions}

Conception and design: Usui, Ichikawa, Tottori. Acquisition of data: Usui, Ichikawa, Tottori, Yamaguchi, Omatsu, Koike, Imai. Analysis and interpretation of data: Usui, Ichikawa, Tottori, Imai. Drafting the article: Ichikawa, Kondo. Critically revising the article: Usui, Ichikawa, Kondo. Reviewed submitted version of manuscript: Usui, Ichikawa, Kondo, Takahashi. Approved the final version of the manuscript on behalf of all authors: Usui. Administrative/technical/material support: Ichikawa, Tottori, Ikeda. Study supervision: Tottori, Takahashi.

\section{Correspondence}

Naotaka Usui: National Epilepsy Center, NHO Shizuoka Institute of Epilepsy and Neurological Disorders, Shizuoka, Japan. usui-nsu@umin. ac.jp. 